\title{
Crime and Mental Illness: Impulsivity and Jealousy in a Case of Uxoricide
}

Chiara Sarappa1, Gianpiero Sica ${ }^{1}$, Cecilia Aurino ${ }^{1}$, Stefania Auricchio ${ }^{1}$, Claudio Buccelli², Pierpaolo Di Lorenzo ${ }^{3}$ and Diana Galletta ${ }^{4 *}$

${ }^{1}$ Department of Neurosciences, University of Naples Federico II, Italy

${ }^{2}$ Department of Public Medicine and Social Security, University of Naples Federico II, Italy

${ }^{3}$ Department of Public Medicine and Social Security, University of Naples Federico II, Italy

${ }^{4}$ Division of Clinical Psychodiagnostics and Neuropsychology, University of Naples Federico II, Italy

\begin{abstract}
Psychiatry has always played both a clinical and controller role of social dangerousness, in a culturally accepted vision. This variety of roles appears to be much more evident when psychiatry aims to study the relationships between aggressiveness, impulsivity, mental illness and crime. In those cases, psychiatrists must assess the capability to judge when a crime is committed, that is to say the imputability of a culprit affected by a mental illness, (articles 88 and 89 of the Italian Penal Code). There are cases in which a culprit suffers of a "major" mental illness, such as those belonging to the Axis I of the Diagnostic and Statistical Manual of Mental Disorders IV-Text Revision (DSM IV-TR), or those which the classic psychopathology describes as schizophrenic psychosis or manic-depressive psychosis, but the culprit's capability to distinguish between right and wrong is not impaired; a culprit is affected by a "minor" personality disorder, according to the DSM-IV, or by a psychopathic personality according to the old psychopathologic definition, but the capability to judge may be impaired in different ways.

In the following work, we are going to explore the psychopathological profile of a borderline personality disorder in a case of uxoricide: the motive of the crime is jealousy and it's carrying out arises from impulsivity that is a distinctive trait of this kind of personality. The psychopathological assessment was performed through several clinical interviews for the anamnestic data collection and the diagnostic classification and through a psycho-diagnostic protocol including the Rorschach test and the Minnesota Multiphasic Personality Inventory-2 (MMPI-2).
\end{abstract}

Keywords: Impulsivity; Jealousy; Borderline personality; Psychodiagnosis; Imputability

\section{Introduction}

Psychiatry has always been coated with the clinical role of the controller of dangerous social and public order, because of the relationship between culturally rooted mental illness, aggression and crime, for which the "crazy" is violent and therefore should commit crimes which often are unpredictable and inexplicable: "The criminal acts may result from delusions of any kind, from hallucinations to load the various senses, by the loss of control, which can manifest itself in different ways, the most difficult theme to consider is the so-called impulsive madness... it's enough simple when these pulses occur in people who have suffered from mental illness, while it is much more difficult when the only evidence of insanity is the existence of these pulses, as possible to say that they are simply the result of uncontrolled pleasure of power, very common to all. I should hesitate before accepting the pulses, unless I have evidence of insanity in other family members, such as neurosis or neuralgia or epilepsy in the patient himself" [1].

But the question is considerably more complicated: the aggressiveness that characterizes a specific crime, may have a "pathological" or "physiological" foundation; this difference is not only related to the presence or not of a pre-existing psychiatric disorder diagnosis, but also to the ability to exclude, or greatly diminish, the unable to understand and take action and so the imputability of the subject (Italian Penal Code-art. 88 and 89). Also the chronological connection is considered an important parameter to identify imputability: imputability judgment must be linked at the time of the offense indeed it may happen that a pathological condition was present at the time of the offense and is no longer in place (or attenuated) at the time of forensic psychiatric judgment and this because a pathological condition, as their manifestations, may be not necessarily continuous, stable and incurable, so it is necessary, to forensic psychiatry, to evaluate each clinical case, the causative link, i.e. the connection between the cause of the mental disorder and the kind of crime [2].

The examined case concerns the killing of a spouse "jealousy", as the same author of the crime stated. A sustained violent behaviour from low frustration tolerance the "inability to accept the loss of the love object and the desire to keep it for himself, at any cost, to destroy it, too" [3].

The wife-murder is a male basically crime generally following a history of repeated violence suffered by women. The phenomenon affects all social classes, and it is independent of the of age variable. Until the middle of the last century, adultery was considered the loss of the exclusive right of use to which the treacherous murder of wife was considered as an honour killing [4].

\section{Clinical Case}

Antonio is a 45 year old man who lives in a small village in the hinterland of Campania. He appears tall, strong, with big and strong hands, accustomed to fatigue.

Antonio had a difficult childhood and complicated adolescence: his

*Corresponding author: Diana Galletta, Department of Neurosciences, University of Naples Federico II, School of Medicine, via Pansini n. 5, CAP 80131, Naples, Italy, Tel: +393396515093; E-mail: gallettad@email.it

Received September 23, 2013; Accepted October 29, 2013; Published October 31,2013

Citation: Sarappa C, Sica G, Aurino C, Auricchio S, Buccelli C, et al. (2013) Crime and Mental Illness: Impulsivity and Jealousy in a Case of Uxoricide. J Forensic Res 4: 202. doi:10.4172/2157-7145.1000202

Copyright: @ 2013 Sarappa C, et al. This is an open-access article distributed under the terms of the Creative Commons Attribution License, which permits unrestricted use, distribution, and reproduction in any medium, provided the original author and source are credited. 
mother died when he was very young, his father didn't care of him, so he lived in an orphanage; academic difficulties, problematic interpersonal relationships and violent behaviours. The doubts concerning the perception of himself and complicated interpersonal relationships, made him feel a chronic feeling of emptiness, inappropriate and intense dysphoria and a difficulty in controlling impulses.

He completed the secondary school and found a job for a company; his job consisted in driving and governing a machine steamroller. His only entertainment was having a drink with the usual friends at the pub of the small village.

The pub is a place for relaxation, it is often a hotbed of gossip, stories, intrigue, it is the right place where it's possible to perform and display showing off in front of other people.

Antonio got married when he was 40 with a woman 20 years younger than him, after a period of complicated interpersonal relationships. He had a daughter but he didn't care of her.

Antonio lived in a small town where the socio-cultural backwardness prevails and women are often subordinated to men, especially to their husbands. Antonio often set the domain on his wife by force. The marital relationship has been characterized, several times, by the dismissal of the wife to escape the violence of her husband; she took refuge in his mother's house, which always ended up with the return to the house of the spouse.

The economic hardships induced his wife to look for a job. In the pub where Antonio spent his free time, the event became a topic of conversation, everyone spread rumour about an attempt to emancipation and how this should be a dishonour for Antonio, a sign of weakness.

Antonio's wife was seen talking in a public place with a man, her future employer, and then moving away together in a car. Antonio was immediately informed about this and driving his van, chased the car, exceeded them, cut them off and stopped them. He began to shake the car and kicked and punched to it. The frightened wife went down, carelessly, and became to run away. Antonio followed her, reached her and started to beat her with violence by filling her with insults. Exhausted, he started driving his van without realizing that the woman was lying on the asphalt, dead. The man who accompanied her, confused, after having ascertained the death of the woman, called the police who then communicated to Antonio the outcome of his impulse of violence. Antonio underwent a psycho-diagnostic path for the study of the psychological profile and the structure of personality.

The psychopathological assessment was performed through several clinical interviews for the anamnestic data collection and the diagnostic classification and through a psycho-diagnostic protocol including the Rorschach test and the Minnesota Multiphasic Personality Inventory-2 (MMPI-2).

In Italy when a technical advice is requested to assess the imputability of a potential culprit two main tests are usually performed: the Minnesota Multiphasic Personality Inventory-2 (MMPI-2) and the Rorschach test.

The MMPI-2 comprises 10 Clinical Scales and 15 Content Scales whose scores are considered normal when the results are equal or below the cut-off point of 65 .

The Rorschach is a projective test with no specific cut-off scores, therefore its outcome is the result of a correlation of the various indexes of the test and the relationship that those indexes may have when confronted to other tests performed during the psycho diagnostic evaluation.

\section{Discussion}

In the days that accompanied the legal process, a request for technical advice was made (CTU), Antonio underwent a psychodiagnostic path for the study of the psychological profile and the structure of personality.

The psychodiagnostic examination, preceded and followed by clinical interviews, contemplated the Rorschach test and the Minnesota Multiphasic Personality Inventory-2 (MMPI-2).

The MMPI-2 Clinical Scales scores expressed noteworthy scores to the paranoia scale $73 \%$ and $67 \%$ social introversion. The Scale of Content showed elevated scores for: obsessiveness $67 \%$; depression $71 \%$; health concern $74 \%$; anger $67 \%$; cynicism $69 \%$; low self-esteem $68 \%$; difficulty in treatment $84 \%$. Additional Scale showed just one significant score: Marital Distress 71\%. Subscale of Wiener and Harmon had not been recorded scores of clinical interest. Harris-Lingoes subscale scores showed only significant pathological subscale: Amorality $66 \%$.

Subscales of the $\mathrm{Si}$ (social introversion) showed shyness/ embarrassment $78 \%$. The indexes derived from the fundamental or clinical scales allow a more accurate assessment of a number of personality dimension: the Frustration Tolerance Index (FTI) showed a low tolerance to frustration, the Anxiety Index AI=62.56 (normal value 35-65), the Neurotic Score NS=59 (normal value 35-65), the Psychotic Score PS=63.66 (normal value 35-65), the Organic Sign Index: OSI=72 and the Index of Psychopathology IP=87 (values above 45 indicate inclusion in the psychotic area); the Dissimulation Index DFK=1.79 (a value between -12 and +8 indicates the absence of concealment); the Passive-Aggressive Index PAI=-46. This index discriminates between the tell-tale signs of aggression/liabilities, the score- 46 is compatible with an aggressive trait.

The analysis of the MMPI-2 protocol made it possible to highlight a conformist attitude that was joined by the presence of a state of emotional distress. The subject expressed a tendency to avoid situations of social interaction in which he had difficulty in entering without discomfort and embarrassment. It also showed projective trends interpretation: in interpersonal relationships, he appeared rigid and suspicious, he tended to withdraw into himself; sometimes he had somatization disorders.

Stood the difficulty of emotional control tending to push the subject to closure and the development of fantasies, as an alternative to an adequate interpersonal interaction. In conditions of high stress he could manifest emotional liability and acting-out.

At the Rorschach test as part of a productivity quantitatively not high $(\mathrm{R}=15)$ and qualitatively little changed, is possible caught a wealth determinants instinctual affective charge $(\mathrm{FM}=3)$ and low in mature energy $(M=1)$. The type of Intima resonance appeared extratensiva, the subject, used with difficulty their resources and intimate interior experiences so to meet their basic needs demanding immediate satisfaction of needs through the "emotional discharge" to the outside, so that seems incapable to postpone and process.

Antonio could not exercise sufficient control over emotional impulses, as confirmed by the Index of Impulsivity whose value is 0.25 (normal range 0.35 to 0.9 ) and the prevalence of $\mathrm{C}$ and $\mathrm{CF}$ on the response FC (index of adaptation, stabilization and affective communication). The presence of the responses $\mathrm{C}$ indicates that it's not 
always put in place a control on the affective manifestations resulting in reduced self-mastery over their feelings as to make possible, in particular stress conditions, an impulse low control. Antonio has a reduced responsiveness to environmental stimuli, the average response time was in fact 60 " (normal range, 30"). Slow responses could depend on a reactive emotional depression compatible with the condition of imprisonment. The emotional needs were recognized but poorly integrated into the personality, the lack of answers M (human movement) suggest a reduced susceptibility to analyze relationships with small introspective abilities.

From a careful analysis of the protocol emerged, in addition, a limited degree of aspiration, in tune with the intellectual capacity and the level of cultural origin. The Index of Reality, equal to 5 appears normal (normal 5-7).

The protocol as a whole expressed a double psychic functioning: on one hand stiff, conformist and banal, on the other disorganized, projective, close to the disintegration with signals of an alarm state of the inner world. The content analysis of the responses showed disturbing references to the burden of human annihilation anxiety represented.

The sensorial determinants that placed in the colour responses, show a direct associations which highlight the excessive responsiveness to external stimuli showing all "the envelop psychic fragility that easily vanish when the excitement grows" $[5,6]$.

The clinical observations and the data obtained, confirm the psychodiagnosis feelings of dependency, inadequacy, inability to accept frustration of the refusal to tolerate defeat, and led to a diagnosis of borderline personality structure in a subject with guidelines on interpretation and reference.

The specific tract symptoms who had scared the Antonio behaviour was impulsiveness, then expressed in destructive anger.

“...Will be the persistent feelings of emptiness, emotional instability and of deep emotional experiences of loss that permeate all the love and sentimental borderline personality structures to support the destructive anger and, lastly, especially in situations of abandonment suffered, true or perceived as such, the transition to a violent act can be supported by a paranoid ideation" [3]. For Antonio, separation, real or perceived, fuelled the abandoning anguish. The paranoid traits, emerged at the psychodiagnosis, supported the false conviction of treason. The feeling of jealousy thus appeared exasperated by a psychopathological dimension.

The forensic psychiatric team's opinion was that Antonio showed huge difficulties in distinguishing right and wrong because of his psychopathological profile as above mentioned. His low self-control appeared evident at the moment of the clinical assessment but it is only presumable when he committed the crime.

About the imputably, in the presence of a crime motivated by jealousy, like Antonio's one, also in front of a killing behavior caused by delirious, it is necessary to remember that the mental disorder is just one of the elements of the offense and that underlining the presence of a mental disorder would be too simplistic to classify a possible violent behavior motivated by jealousy as a mental defect.

The Court's final decision was that Antonio had to be judged guilty of homicide.

\section{Conclusions}

The research of the relationship between mental illness, aggression and crime is the reason why psychiatry, has always taken both clinical role and a role of controller social danger and public order. Over the centuries, the relationship between mental illness and crime was discussed according to the cultural and political settings of the moment, but the first author who organized a definite theory was Cesare Lombroso who on the basis of Darwin's thought, elaborated the global bio-antropologic theory crime according to which offenders may be characterized by somatic and/or constitutional abnormalities.

According to this theory there are various types of criminals: the "biological" or "born criminal" or "morally insane" or "epileptic", which highlights the characteristics of a typical degenerative ancestral or primitive stage of evolution of the human race that does not allow an adequate adaptation to society and urges him to commit the crime, and the "criminal type" which includes the "fortuitous delinquent" that can evolve into the "habits delinquent" and the "passion thug" which presents a temporary blurred moral sense when the crime is made. Many authors have supported the Lombrosian hypothesis, finding correlations in electroencephalography or neuroimaging, between deviant behavior and altered processes and brain functions [7-12]. Many supporters of the biological theories, to explain criminal behaviour, suggest that the interrelationship between biological and social factors, that can amplify, reduce or cancel the effects of biological factors [13].

More recently, different answers have been formulated to explain the relationship between mental illness and criminality: "medicalization" for which many criminals have antisocial chronic behavior that cultural systems don't understand so that they are evaluated just in the psychiatric area [14]; "criminalization" as a result of deinstitutionalization of mental illness: subject come to psychiatry only after the offense has been legally punished [15].

There are many epidemiological studies designed to understand the possible relationship between crime and mental disorders. The results of these studies are often in conflict: many authors [16-24] have claimed a higher frequency of mental health problems in offenders. In fact these studies show as bias the fact that have included, in the evaluation, also alcohol, addicted subjects and have not considered the role of the prison in determining the psychopathology [25]. In addition, epidemiological and statistical studies have estimated a high presence of substance abusers or offenders with a diagnosis of antisocial personality disorder that validates the hypothesis of a causal relationship between mental illness and crime, so that the "disturbed psychic" are as much as the "not disturbed" and the majority of offenders do not exhibit mental disorders [26-28]. Some authors claimed the possibility to predict deviant behavior bearing in mind variables related to personality factors, such as the type of motivation to violence (emotional or instrumental), the type of inhibition, the intensity and the habit versus deviant behaviour (linked to the reinforcements) and situational factors such as the possibility of finding weapons, victim behaviour, subcultural values $[29,30]$.

In any case, there is a recruitment bias due to the fact that the psychiatric examination for the evaluation of the offender imputability, is required only for heavy offenses and not for minor ones. In addition, until March of 2005, the relationship between mental illness and crime, included the psychiatric diagnostic categories as "major" in which personality disorders were excluded. The judgment of the Court of Cassation United Sections Penalty-No. 9163 ud. January 25, 2005dep. March 8, 2005 ruled that "Even the personality disorders, such as neurosis and psychopathy, may be due likely to exclude or greatly diminish, autonomely and specificly, the unable to understand and 
Citation: Sarappa C, Sica G, Aurino C, Auricchio S, Buccelli C, et al. (2013) Crime and Mental Illness: Impulsivity and Jealousy in a Case of Uxoricide. J Forensic Res 4: 202. doi:10.4172/2157-7145.1000202

Page 4 of 4

take action-Articles. 88 and 89 of the Penal Code, provided they are of consistency, intensity, importance and seriousness to affect the same; conversely, do not assume importance for the purposes of imputably other character anomalies and passionate emotional states, which didn't show connotations of incisiveness about the ability of selfdetermination; it is also necessary that between the mental disorder and the offense there is a causal link, to permit the inference that second causally determined by the first".

The current forensic psychiatric approach requires evaluation of imputability strictly anchored to the examination of individual clinical case, disconnecting from math equation, too rooted in the social culture, "psychiatric illness=aggression=crime". Actually it is inappropriate the criterion that a given diagnosis should be required to pay a judgment of inability to understand and take action: there are disturbed individuals, with varying degrees of impairment, and not as a disease entity ontologically due. It is also essential that at categorical diagnosis should follow the functional one: the categorical analysis allows nosographic placement of the disorder according to the criteria of Diagnostic and Statistical Manual of Mental Disorders IV Text Revision (DSM IV-TR) or of the International Statistical Classification of Diseases and Related Health Problems No. 10 (ICD 10). Functional diagnosis allows to verify the functional impairment, and relative degree, that the diagnosed disorder resulted in the organization and functioning of a specific personality $[31,32]$.

\section{References}

1. Savage GH, FRCP (1886) Drunkenness in relation to criminal responsibility. The British Journal of Psychiatry 32: 23-30.

2. Fiadanca G, Musco E (2001) Diritto penale-Parte generale. ( $4^{\text {th }}$ edn), Zanichelli Editore, Bologna, Italy.

3. Catanesi R, Carabellese F (2008) Uccidere per gelosia Rivista Italiana di Medicina Legale 95.

4. Galletta D, Sarappa C, Casiello M, Giuliani B (2009) [Personality disorder and penal imputability: a case of uxoricide in a expert's report]. Riv Psichiatr 44: 191-195.

5. Chabert C (2003) Psicopatologia e Rorschach. Raffaello Cortina Editore Milano, Italy.

6. Freud S (1915-1917) Pulsioni e loro destini. OSF in opere edite da Boringhieri per la traduzione italiana degli scritti di Freud S, Torino 1980

7. Raine A (1993) The Psychopathology of Crime. Criminal Behavior as a Clinical Disorder, Academic Press, San Diego, USA.

8. Mednick SA, Volavka J (1980) Biology and Crime. In: Morris N, Tonry M (a cura di): Crime and justice. An annual review of research, The University of Chicago Press, Chicago.

9. Blackburn R (1993) The Psychology of criminal conduct: Theory, Research and Practice", John Wright \& Sons, Chichester West Sussex, United Kingdom.

10. Lewis DO, Pincus JH, Bard B, Richardson E, Prichep LS, et al. (1988) Neuropsychiatric, psychoeducational, and family characteristics of 14 juveniles condemned to death in the United States. Am J Psychiatry 145: 584-589.

11. Venables PH (1988) Psychophisiology and crime. Theory and data. In: Moffitt TE, Mednick SA (a cura di): Biological Contributions to crime causation, Martinus Nijhoff, Holland.

12. Raine A, Buchsbaumm S, Laclasse $L$ (1997) Brain Abnormalities in murderers indicated by Positron Emission Tomography. Biological Psychiatry 42: 495-508.

13. Bandini T (2003) La personalità del delinquent. In: BANDINI T (a curadi): Criminologia.

14. Hodgins S (1994) Les malate mentaux face à la justice criminelle", In: Szabo D, Le Blance M (a cura di): "Traité de Criminologie Empirique", Les presses de l'Université de Montréal.
15. Laster K, Glaser W (1990) Are the mentally ill being criminalized? Admissions of prisoners to psychiatric hospitals before and after the 1986 Mental Health Act (Victoria)". Australian \& New Zealand Journal of Criminology 23: 230-240.

16. Roth L (1980) Correctional Psychiatry. In: Curran W, Mcgarry A, Petty C (a cura di): Modern Legal Medicine, Psychiatry and Forensic Science, Davis, Philadelphia, USA

17. Collins JJ, Schelenger WE (1983) The prevalence of psychiatric disorder among admission to prison. Oral presentation at the Annual Meeting of the American Society of Criminology, Denver, USA

18. Daniel AE, Bobins AJ, Reid JC, Wilfley DE (1988) Lifetime and six-month prevalence of psychiatric disorders among sentenced female offenders. Bull Am Acad Psychiatry Law 16: 333-342.

19. Hyde PS, Seiter RP (1987) The prevalence of mental illness among inmates in the Ohio prison system. The Department of Mental Health and the Ohio Department of Rehabilitation and Correction Interdepartmental Planning and Oversight Committee for Psychiatric Services to Correction.

20. Neighbors HW, Williams D, Gunnings T, Lipscomb W, Broman C, et al. (1987) The prevalence of mental disorder in Michigan prisons. Final Report submitted to the Michigan Department of Correction, University of Michigan and Michigan State University.

21. Teplin LA (1990) The prevalence of severe mental disorder among male urban jail detainees: comparison with the epidemiologic catchment area program. Am J Public Health 80: 663-669.

22. Hodgins S, Cote G (1990) Prevalence des troubles mentaux chez les detenus des penitencieres du Quebec. Sante Mentale au Canada 38: 1.

23. Hodgins $\mathrm{S}$, Cotè $\mathrm{G}$ (1991) The mental health of penitentiary inmates in isolation Canadian Journal of Criminology 33: 175-182.

24. Motiuk LL, Porporino FJ (1991) The prevalence, nature and severity of menta health problems among federal male inmates in Canadian penitentiaries. Research and Statistics Branch, Correctional Service Canada 24.

25. Gibbs JJ (1987) Symptoms of psychopathology among jail prisoners. Crimina Justice and Behavior 14: 288-310.

26. Monahan JD (1981) The clinical prediction of violent behavior. United States Department of Health and Human Service, Public Health Service, Alcohol, Drug Abuse, and Mental Health administration, National Institute of Mental Health.

27. Guze SB, Woodruff RA, Clayton PJ (1974) Psychiatric Disorders and Criminality. Journal of the American Medical Association 227: 641-642.

28. Bland RC, Newman SC, Thompson AH, Dyck RJ (1998) Psychiatric Disorders in the population and in prisoners. International Journal of Law and Psychiatry 21: 273.

29. Megargee El (1976) The prediction of dangerous behavior. Criminal Justice and Behavior 3: 3-22.

30. Bandini T (2003 b) Disturbo psichico e criminalità. In: Bandini T (a curadi): Criminologia 2: 161-238.

31. Fornari U (2013) Trattato di Psichiatria Forense ( $5^{\text {th }}$ edn), Utet, Torino, Italy.

32. Ponti G (1999) Compendio di Criminologia ( $4^{\text {th }}$ edn), Raffaello Cortina Editore, Milano, Italy. 